\title{
Corrosion Resistance of Cu-Alloyed Precipitation Hardenable Duplex Stainless Steel ASTM A890 Grade 1B
}

\author{
Hillane Mirelle Lopes Ferreira de Lima ${ }^{a}{ }^{\oplus}$, Sérgio Souto Maior Tavares ${ }^{b}{ }^{\circledR}$, Ivan Napoleão Bastos $^{c}$,
}

\author{
Matheus Souza Rodrigues ${ }^{a}$, Marcelo Martins ${ }^{d \oplus, \text { Walney Silva Araújo }}{ }^{a}$ \\ ${ }^{a}$ Departamento de Engenharia Metalúrgica e Materiais, Universidade Federal do Ceará, \\ Fortaleza, CE, Brasil \\ ${ }^{b}$ Departamento de Engenharia Mecânica, Universidade Federal Fluminense, Niterói, RJ, Brasil \\ ${ }^{c}$ Departamento de Materiais, Instituto Politécnico, Universidade do Estado de Rio de Janeiro, \\ Nova Friburgo, RJ, Brasil \\ ${ }^{d}$ Departamento de Engenharia Elétrica, Centro Universitário Salesiano São Paulo, Americana, SP, Brasil
}

Received: December 05, 2018; Revised: August 09, 2019; Accepted: September 18, 2019

\begin{abstract}
Duplex stainless steels (DSS) are corrosion resistant alloys largely used in chemical and petrochemical industries. Some commercial DSS contain $0.5-1.0 \%$ copper addition to improve the corrosion resistance by reducing the corrosion rate in non-oxidizing environments. Higher copper addition $(\geq 2 \%)$ can also hard by precipitation, especially when fine copper precipitates ( $\varepsilon$ phase) are produced. In this work, a cast copper alloyed DSS type ASTM A890 grade 1B with $3.01 \% \mathrm{Cu}$ was investigated. Different levels of hardness were produced by solution treatment and aging at $450,500,550$ and $600{ }^{\circ} \mathrm{C}$ for periods of time up to 1 hour. The corrosion resistance of aged DSS was evaluated by electrochemical tests in three media: $0.6 \mathrm{~mol} / \mathrm{L} \mathrm{NaCl}, 0.3 \mathrm{~mol} / \mathrm{L} \mathrm{H}_{2} \mathrm{SO}_{4}$ and $0.6 \mathrm{~mol} / \mathrm{L} \mathrm{NaCl}+0.3 \mathrm{~mol} / \mathrm{L} \mathrm{H}_{2} \mathrm{SO}_{4}$ solutions. The results indicate that the effect of $\mathrm{Cu}$ addition depends on the media studied. Polarization studies in $0.6 \mathrm{~mol} / \mathrm{L} \mathrm{NaCl}$ showed a small anodic current peak occurred at around $400 \mathrm{mV} \mathrm{vs.} \mathrm{Ag} / \mathrm{AgCl}$, with a strong influence on the passive film stability. Additionally, chronoamperometric measurements at $400 \mathrm{mV}$ vs. $\mathrm{Ag} / \mathrm{AgCl}$ showed a high electrochemical activity for the samples in $0.6 \mathrm{~mol} / \mathrm{L} \mathrm{NaCl}$.
\end{abstract}

Keywords: Cast duplex stainless steel, copper, passive film.

\section{Introduction}

Duplex stainless steels (DSS) are corrosion resistant alloys largely used in chemical and petrochemical industries. DSS contain approximately equal volume fractions (about $50 \%$ ) of ferrite $(\alpha)$ and austenite $(\gamma)$, and large amounts of key passivating elements $(\mathrm{Cr}, \mathrm{Ni} \text { and } \mathrm{Mo})^{1-3}$. However, when exposed to temperatures over $300^{\circ} \mathrm{C}$, these steels can suffer age hardening and embrittlement. This phenomenon is caused by precipitation of secondary phases, whilst the precipitation kinetics is accelerated by higher alloying ${ }^{4-6}$.

The copper addition reduces the corrosion rate in non-oxidizing environments, notably in sulfuric acid ${ }^{7}$. Additionally, the higher copper addition ( $\geq 2 \%$ ) favors the precipitation hardening, as observed in some stainless steels such as 17-4PH martensitic steel. Aging after solution treatment causes significant hardening by precipitation of fine copper precipitates ( $\varepsilon$-phase). However, the influence of copper alloying on stainless steel passivation is still controversial mainly in the literature regarding the diversity of composition and experimental conditions $(\mathrm{pH}$, temperature, chloride concentration, for example) ${ }^{8,9}$.
It is known that the most passive films on stainless steels are semiconducting, and although their electrochemical behavior has been studied widely, the exact electronic structure has not yet fully established ${ }^{10-12}$. Despite widespread interest in correlating the formation and breakdown of passive oxide films with the electronic structure, the influence of $\mathrm{Cu}$ on the electronic properties of stainless steels is still limited, but is known that alters the donor or acceptor densities in passive film on the DSS ${ }^{10}$. In the present paper, the effect of $\mathrm{Cu}$ addition on passivation properties of cast duplex stainless steel was studied by electrochemical technique.

The purpose of this work was to characterize the hardness and passivation behavior of a cast copper alloyed DSS type ASTM A890 grade 1B in different aggressive environments. The effect of short duration aging was also investigated by comparing the results of specimens aged with the solution treated samples. Microstructural characterization was performed by optical and scanning electron microscopy. 


\section{Experimental}

The cast DSS ASTM A890 grade 1B used in this work was provided by Sulzer Brazil SA and the elemental composition is presented in Table 1. The samples were solution annealed at $1100{ }^{\circ} \mathrm{C}$ for $1.0 \mathrm{~h}$, followed by water quenched to homogenize the microstructures. After this stage, the samples were subjected to isothermal heat treatments from 450 to $600{ }^{\circ} \mathrm{C}$ for periods up to $1.0 \mathrm{~h}$. Vickers hardness (HV) was measured with a $10 \mathrm{kgf}$ load and measured at least six times for each microstructure. Microstructural examination of specimens was conducted using light optical microscopy (MO) and scanning electron microscopy (SEM) with energy dispersive spectrometer (EDS). The microstructures were revealed by Beraha reagent $\left(20 \mathrm{~mL} \mathrm{HCl}, 80 \mathrm{~mL} \mathrm{H}_{2} \mathrm{O}\right.$, and $1.0 \mathrm{~g}$ of potassium metabisulfide) and the volume fraction of ferrite and austenite was evaluated by quantitative metallography based on light optical microscopy. The volume fraction was estimated from the MO images using the freeware ImageJ.

The electrochemical measurements were carried out using a potentiostat-galvanostat Autolab model PGSTAT302N with a conventional three-electrode cell containing a platinum grid as auxiliary electrode and a saturated $\mathrm{KCl}$ silver/silver chloride $(\mathrm{Ag} / \mathrm{AgCl})$ as reference. The DSS was the working electrode was embedded in epoxy resin and the area exposed to the test solution was approximately $0.3 \mathrm{~cm}^{2}$. The interface between sample and resin were coated with transparent lacquer to avoid crevices. Prior to each measurement, the working electrode was abraded with silicon carbide emery paper up to 600 grit, degreased with ethanol, rinsed with distilled water and dried in hot air. Three solutions were used at room temperature: i) $0.6 \mathrm{~mol} / \mathrm{L} \mathrm{NaCl}$, ii) $0.3 \mathrm{~mol} / \mathrm{L}$ $\mathrm{H}_{2} \mathrm{SO}_{4}$ and iii) $0.6 \mathrm{~mol} / \mathrm{L} \mathrm{NaCl}+0.3 \mathrm{~mol} / \mathrm{L} \mathrm{H}_{2} \mathrm{SO}_{4}$. The working electrodes were initially immersed in the solution at open circuit potential (OCP) sufficient time to reach the steady-state potential.

Cyclic polarization tests were measured potentiodynamically at a scan rate of $1.0 \mathrm{mVs}^{-1}$ until the current density of 1.0 $\mathrm{mAcm}^{-2}$ was reached and the potential scanning direction was reversed. Chronoamperometry was used to evaluate the evolution of the current density flowing into the cell as a function of the time by application of constant potential for $1.0 \mathrm{~h}$. Mott-Schottky measurement was carried out on the passive potential range with a $10 \mathrm{mV}$ sinusoidal wave at a fixed frequency of $10 \mathrm{~Hz}^{13}$ and initiated at $200 \mathrm{mV}$ vs. Ag/ $\mathrm{AgCl} \mathrm{KCl}$ saturated and potential step of $25 \mathrm{mV}$.

\section{Results and Discussion}

\subsection{Microstructural characterization}

Figure 1(a) shows the optical micrography of microstructure of the specimens after the solution treatment at $1100{ }^{\circ} \mathrm{C}$ for $1.0 \mathrm{~h}$. The austenite phase $(\gamma)$ is shown as bright while the dark region is the ferrite phase $(\alpha)$. The island-like $\gamma$ phase was surrounded by the continuous $\alpha$ matrix. The volume fraction of the each phase was calculated via image analysis and revealed about $48 \% \gamma$ and $52 \% \alpha$, indicating a good balance of phases. This balance remained unchanged with aging time. Although the OM data did not show significant microstructural changes in the samples, copper additions up to $1 \%$ favors $\varepsilon$-phase precipitation ${ }^{3,14}$. As the alloy studied has $3.01 \% \mathrm{Cu}$ (Table 1), an additional amount of extra-fine precipitate is expected. However, the grains of $\varepsilon$-phase contained up to $96 \% \mathrm{Cu}$ and they are very small $(<30 \mathrm{~nm})^{15}$, making it undetectable in OM analysis. Moreover, inclusions with spherical shape may be observed in Figure 1(b) (highlighted by red ellipses). These inclusions are typical of cast DSS and may act as sites of deleterious phases nucleation ${ }^{16}$. Polished specimens were observed using SEM/EDS to investigate the composition of inclusions. The backscattered electron image of Figure 2(a) shows that the non-metallic inclusions are uniformly distributed in the material. Figure 2(b) presents one of the inclusions and the corresponding EDS maps for elements $\mathrm{O}, \mathrm{Ca}, \mathrm{Mn}, \mathrm{Al}, \mathrm{Si}$ and $\mathrm{Cu}$.

\subsection{Mechanical properties}

Figure 3 depicts the Vickers hardness of DSS as a function of aging time. The hardness increases rapidly at the beginning of aging for $450-600{ }^{\circ} \mathrm{C}$ range and the values are between the range of 260 and $280 \mathrm{HV}$ with 5 min aging. The hardness of aged microstructure is higher than that of the solid solution state. Longer aging time increases significantly the hardness for the sample aged at $450{ }^{\circ} \mathrm{C}$. For the microstructures treated at 550 and $600{ }^{\circ} \mathrm{C}$, a lower hardness is observed up to 1.0 hour, characterizing an overaging process. Nevertheless, the hardness after aging at 500, 550 and $600{ }^{\circ} \mathrm{C}$ were greater than the solid treated specimen. Higher copper addition ( $\geq 2 \%$ ) combined with low temperature aging provokes significant hardening by fine copper precipitation ( $\varepsilon$-phase). Moreover, previous works ${ }^{17-19}$ suggested that aging of DSSs in the range of temperature between 350 and $600{ }^{\circ} \mathrm{C}$ would cause the

Table 1. Elemental composition of DSS (\% wt.).

\begin{tabular}{|c|c|c|c|c|c|c|c|c|c|}
\hline & C & $\mathrm{Cr}$ & $\mathrm{Ni}$ & Mn & Si & Mo & $\mathrm{Cu}$ & $\mathbf{N}$ & $\mathrm{Fe}$ \\
\hline 1B & 0.043 & 25.64 & 4.51 & 0.68 & 0.80 & 2.01 & 3.01 & 0.21 & Bal. \\
\hline
\end{tabular}


(a)

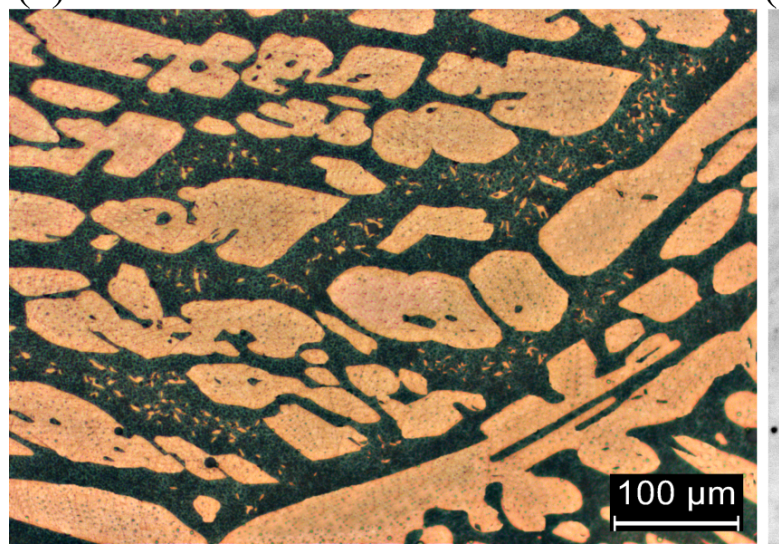

(b)

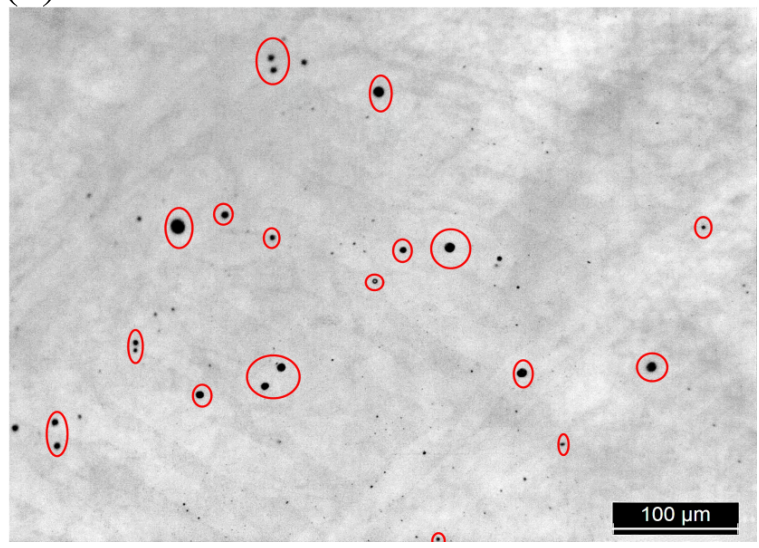

Figure 1. Typical microstructure of the cast DSS after solution annealing. (a) Beraha etching, (b) Polished sample with red marks around inclusions.

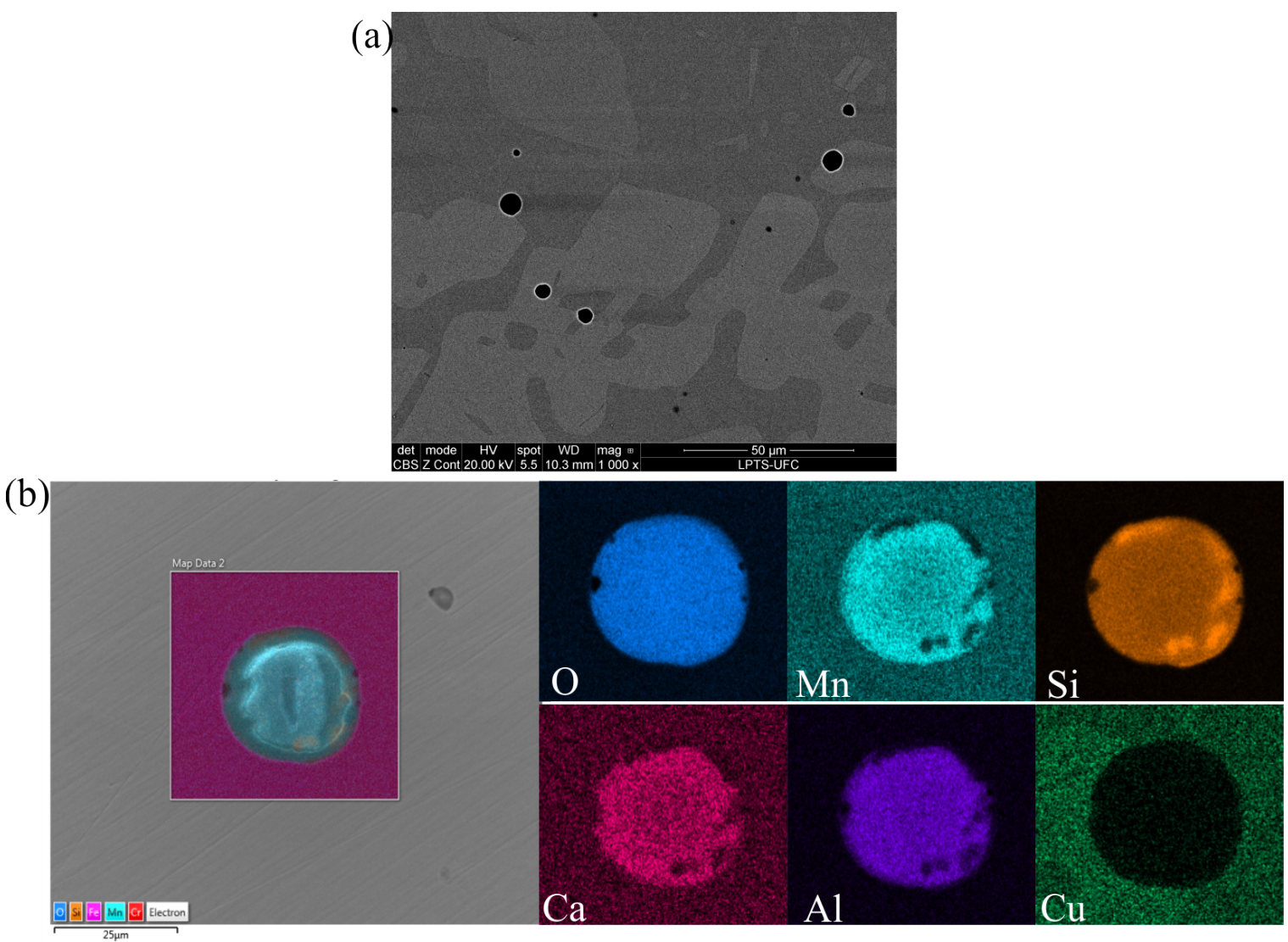

Figure 2. (a) Round inclusions observed on the surface of DSS, with (b) the maps for elements $\mathrm{O}, \mathrm{Mn}, \mathrm{Si}, \mathrm{Ca}, \mathrm{Al}$ and $\mathrm{Cu}$.

spinodal decomposition of the ferrite into chromium-rich $\left(\alpha^{\prime}\right)$ and chromium-depleted $\left(\alpha^{\prime \prime}\right)$ phases. Therefore, the higher hardness values of aged samples may be attributed to $\alpha^{\prime}$ and $\varepsilon$-phase precipitation. Sigma $(\sigma)$ and $\operatorname{chi}(\chi)$ phases are not prone to precipitate in such low temperatures, and in fact they were not observed in the microstructures.

The interest in the initial stage of age hardening is the possibility to perform heat treatments capable of hardening the material, with minimum deleterious effects on corrosion resistance. This processing is especially important to cast pieces whose mechanical properties cannot be improved by thermomechanical treatment. In order to evaluate this possibility, short duration heat treatments were performed for a deeper analysis of corrosion tests in the ASTM A890 1B steel grade. The corrosion tests were applied to samples aged for 1.0 hour. 


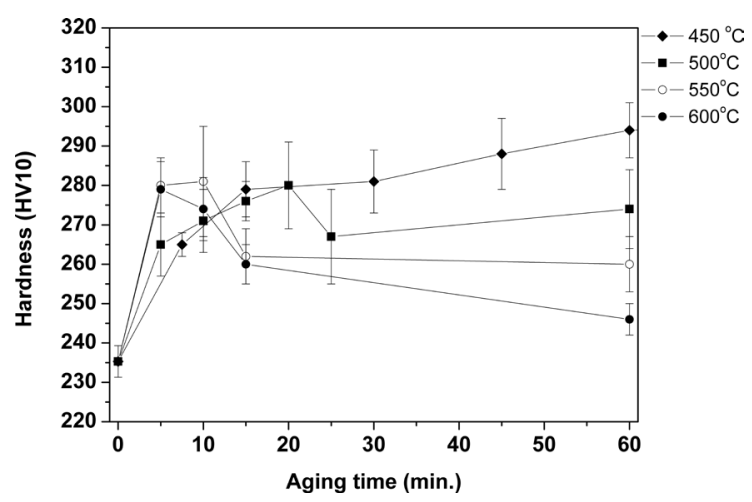

Figure 3. Hardness of samples after solution annealing and aging treatments.

\subsection{Potentiodynamic polarization tests}

Figure 4 shows the cyclic potentiodynamic polarization curves of the solution-treated and aged samples of DSS in $0.6 \mathrm{~mol} / \mathrm{L} \mathrm{NaCl}, 0.3 \mathrm{~mol} / \mathrm{L} \mathrm{H}_{2} \mathrm{SO}_{4}$ and $0.6 \mathrm{~mol} / \mathrm{L} \mathrm{NaCl}$ $+0.3 \mathrm{~mol} / \mathrm{L} \mathrm{H}_{2} \mathrm{SO}_{4}$ solutions. The acid solutions produce a corrosion potential more positive in comparison with neutral electrolyte.

The results from samples investigated in $0.6 \mathrm{~mol} / \mathrm{L} \mathrm{NaCl}$ (Figure 4(a)) showed that no significant change occurred in the shape of the polarization curves, suggesting that the kinetics of the corrosion processes are not significantly affected by the aging treatments. The polarization curves did not exhibit a distinct active-to-passive transition region, although they showed a wide passive range with current density in the order of few $\mu \mathrm{A} \mathrm{cm}^{-2}$ and breakdown potential around 1.0 $\mathrm{V}$ vs. $\mathrm{Ag} / \mathrm{AgCl}$. The backward curves from $3 \mathrm{mAcm}^{-2}$ show a small hysteresis related to pitting in the solution with 0.6 $\mathrm{mol} / \mathrm{L} \mathrm{NaCl}$. Nevertheless, it can be observed that a small current peak occurred around $400 \mathrm{mV}$ vs. $\mathrm{Ag} / \mathrm{AgCl}$, which is associated with pit nucleation and repassivation ${ }^{20-22}$. The polarization curves in $0.3 \mathrm{~mol} / \mathrm{L} \mathrm{H}_{2} \mathrm{SO}_{4}$ are shown in Figure 4(b). The corrosion potential of DSS in $0.3 \mathrm{~mol} / \mathrm{L} \mathrm{H}_{2} \mathrm{SO}_{4}$ is nobler than in $0.6 \mathrm{~mol} / \mathrm{L} \mathrm{NaCl}$, which may indicate a more active corrosion surface for samples immersed in chloride-containing solution when compared with the specimens immersed in an acidic medium. Indeed, in pure sulfuric acid localized pitting corrosion is not expected to occur. In the acidic chloride media (Figure 4(c)), the peak current observed in $0.6 \mathrm{~mol} / \mathrm{L} \mathrm{NaCl}$ was suppressed by the addition of $0.3 \mathrm{~mol} / \mathrm{L} \mathrm{H}_{2} \mathrm{SO}_{4}$. Since the addition of $\mathrm{Cu}$ improves the corrosion resistance of steel in sulfuric acid, the instability observed only in the polarization curves in chloride solution may be an indication of the effect of the copper on the passivation behavior of samples in this neutral and chloride medium. After the potentiodynamic polarization test the specimen was analyzed by scanning electron microscopy (SEM), and it was possible to observe pits nucleated in the inclusions (Figure 5) that are preferential sites for localized corrosion ${ }^{16}$.

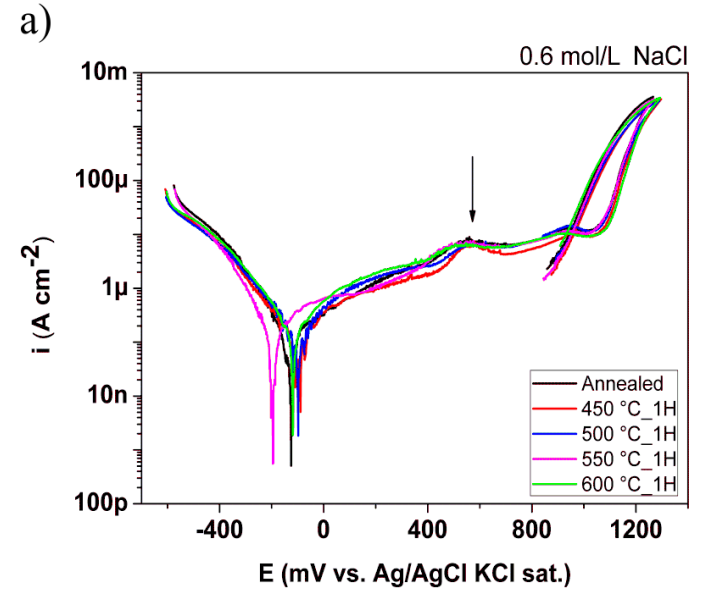

b)
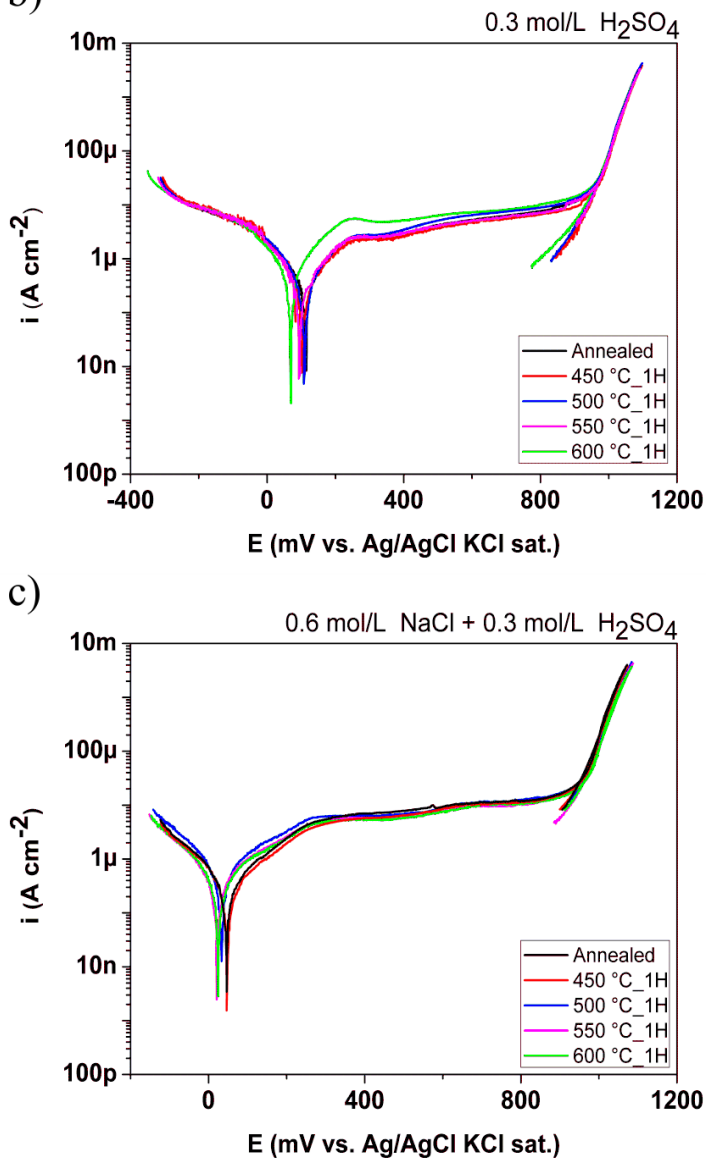

Figure 4. Cyclic polarization curve in (a) $0.6 \mathrm{~mol} / \mathrm{L} \mathrm{NaCl}$, (b) 0.3 $\mathrm{mol} / \mathrm{L} \mathrm{H}_{2} \mathrm{SO}_{4}$ and (c) $0.6 \mathrm{~mol} / \mathrm{L} \mathrm{NaCl}+0.3 \mathrm{~mol} / \mathrm{L} \mathrm{H}_{2} \mathrm{SO}_{4}$ solutions.

\subsection{Chronoamperometric measurements}

Figure 6 shows the current density as a function of time plots at a potential of $400 \mathrm{mV}$ vs. $\mathrm{Ag} / \mathrm{AgCl}$ for $1.0 \mathrm{~h}$ in 0.6 $\mathrm{mol} / \mathrm{L} \mathrm{NaCl}$ (Figure 6(a)), $0.3 \mathrm{~mol} / \mathrm{L} \mathrm{H}_{2} \mathrm{SO}_{4}$ (Figure 6(b)) and $0.6 \mathrm{~mol} / \mathrm{L} \mathrm{NaCl}+0.3 \mathrm{~mol} / \mathrm{L} \mathrm{H}_{2} \mathrm{SO}_{4}$ (Figure 6(c)) solutions. The applied potential of $400 \mathrm{mV}$ vs. $\mathrm{Ag} / \mathrm{AgCl}$ corresponds to the current peak occurrence of polarization curves. The 


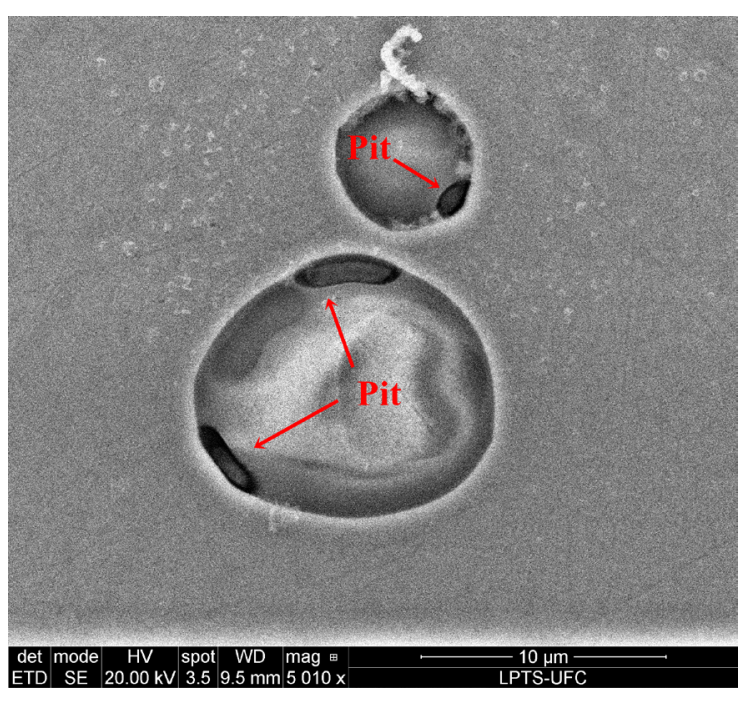

Figure 5. SEM image of annealed specimen after polarization test in $0.6 \mathrm{~mol} / \mathrm{L} \mathrm{NaCl}+0.3 \mathrm{~mol} / \mathrm{L} \mathrm{H}_{2} \mathrm{SO}_{4}$

steady-state current density is an important parameter used to evaluate the kinetics on the metallic surface. Thus, change on the current density at a given potential may be related to the modification in the structure and properties of the passive film ${ }^{23-25}$.

The common feature of these plots is that a large initial current density to a combination of double layer charging and its decrease towards a stable value with passive film growth. The low current suggests that metal dissolution may occur at a very low rate in the passive state, which is a consequence of the formation of a passive film on the sample surface. Additionally, the current transients are closely related to localized corrosion ${ }^{26}$.

As shown in Figure 6(a), it appears that the number of current peaks is considerably larger and with higher amplitude on the samples tested in $0.6 \mathrm{~mol} / \mathrm{L} \mathrm{NaCl}$, showing an increasing electrochemical activity by the chloride in neutral medium. The current spikes correspond to the breakdown and repassivation of metastable pits ${ }^{27,28}$. This suggests that $3.01 \% \mathrm{Cu}$ addition decreases the resistance to pitting corrosion initiation and growth of metastable pits. On the other hand, as shown in Figure 6(c), the samples immersed in $0.6 \mathrm{~mol} / \mathrm{L} \mathrm{NaCl}+0.3 \mathrm{~mol} / \mathrm{L} \mathrm{H}_{2} \mathrm{SO}_{4}$ showed a few current transients and samples immersed in $0.3 \mathrm{~mol} / \mathrm{L}$ $\mathrm{H}_{2} \mathrm{SO}_{4}$ (Figure 6(b)) showed no current transients. This result means that the addition of $\mathrm{Cu}$ decreased the corrosion rate in sulfuric acid solutions, a fact that is in good agreement with other works ${ }^{29-31}$. The mechanism of the improvement of corrosion resistance related to copper addition considered the formation of metallic deposits on a corroded site that hinders the anodic dissolution ${ }^{8,30,31}$.
The time dependency of the potentiostatic current can be expressed by the Equation (1) $)^{32-34}$, where $i_{0}$ represents the initial current and $k$ the slope of the straight lines in double-log plot for current-time transients. It has been pointed out that $k=1$ is usually related to the formation of a compact, high protective passive film, while $k=0.5$ indicates the presence of a porous film growing ${ }^{32-34}$. Table 2 shows the $k$ values for DSS in each experimental condition. The values of $k$ were found to be between the range of 0.40 to 0.48 in 0.6 $\mathrm{mol} / \mathrm{L} \mathrm{NaCl}$, indicating the formation of very porous films growing as a result of a dissolution and precipitation process, between 0.71 to 0.85 for samples immersed in $0.3 \mathrm{~mol} / \mathrm{L}$ $\mathrm{H}_{2} \mathrm{SO}_{4}$, and in acidic $\mathrm{NaCl}$ solution between 0.70 to 0.80 . The experimentally determined values of $k$ suggest that the surface film is more compact in the $0.3 \mathrm{~mol} / \mathrm{L} \mathrm{H}_{2} \mathrm{SO}_{4}$ solution. The $k$ parameter decreasing in the order of media $\mathrm{H}_{2} \mathrm{SO}_{4}>\left(\mathrm{H}_{2} \mathrm{SO}_{4}+\mathrm{NaCl}\right)>\mathrm{NaCl}$, revealing the damage caused by chloride ion on the film. Besides that, the low $k$ and many current transients in chloride medim indicate that the DSS can be susceptible to pitting even with copper content. Additionally, in all solutions, the $k$ values of aged samples is higher than annealed sample, this increase in $k$ is an indication that the protective properties of the passive films are improved with the aging.

$$
i(t)=i_{0} \cdot 10^{-k t}
$$

\subsection{Semiconductor properties of the passive film}

Some works have shown that the corrosion resistance, film breakdown and pit initiation of metal are connected with the semiconducting properties of passive film. Due to the presence of point defects in passive films, these protective nanometer layers behave as extrinsic semiconductors when expose to aqueous solutions. Depending on the predominant defect present in the semiconductive oxide layer of stainless steel, p- or n-type behavior is observed. The passive oxide film with a deficiency in metal ions or excess with cation vacancies generally behaves as p-type, while n-type was developed in the passive films with either by cation transport through interstitial diffusion or by anion diffusion inward toward the metal ${ }^{35-37}$

It is well established that the capacitance behavior of a passive film/electrolyte interface is similar to that of a semiconductor/electrolyte interface ${ }^{38}$. In this way, the effect of the applied potential on capacitance values is described by the Mott-Schottky equation. Based on Mott-Schottky theory, the space charge capacitances of n- or p-type semiconductor (Eq. 2) assuming that the high capacitance of the Helmholtz layer could be neglected in a series connection: 
(a)

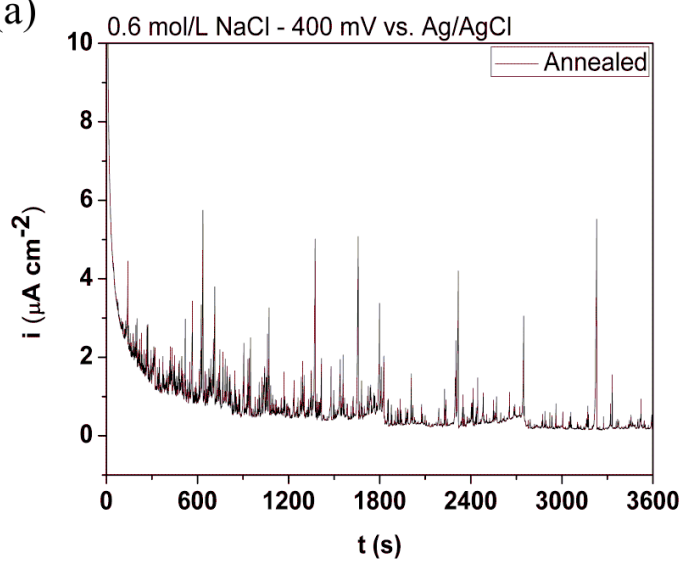

(b)

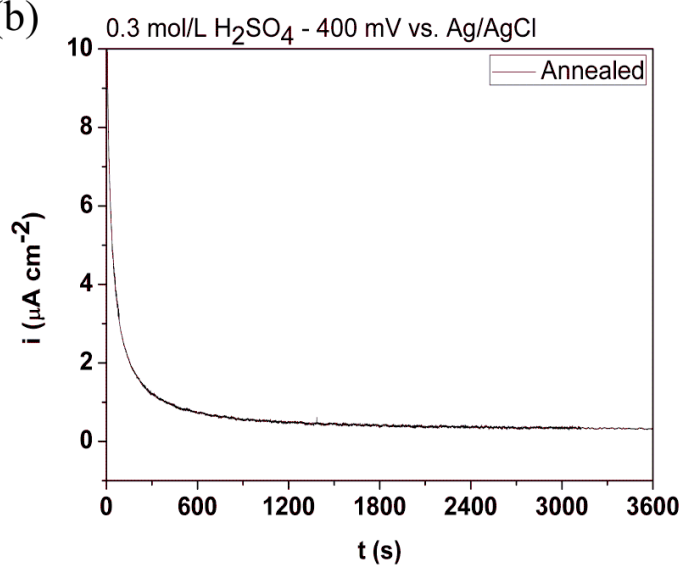

(c) $0.6 \mathrm{~mol} / \mathrm{L} \mathrm{NaCl}+0.3 \mathrm{~mol} / \mathrm{L} \mathrm{H}_{2} \mathrm{SO}_{4}-400 \mathrm{mV}$ vs. Ag/AgCl

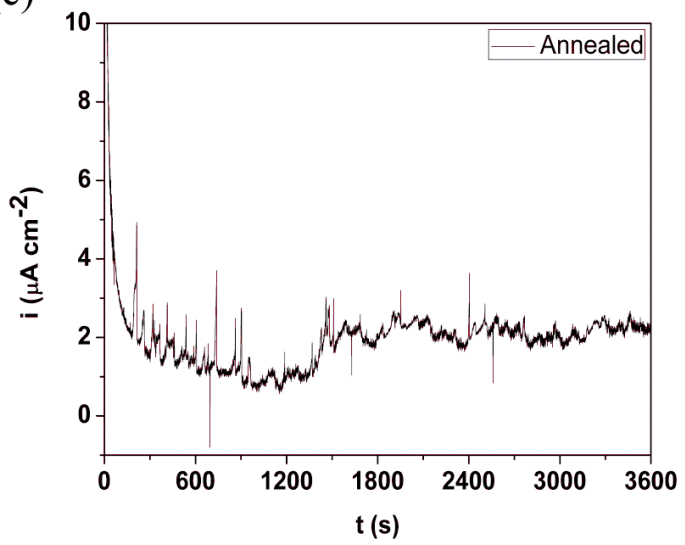

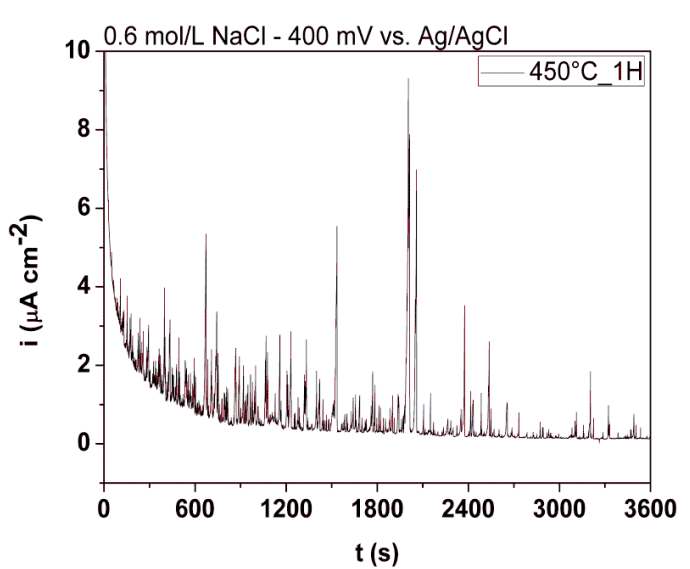

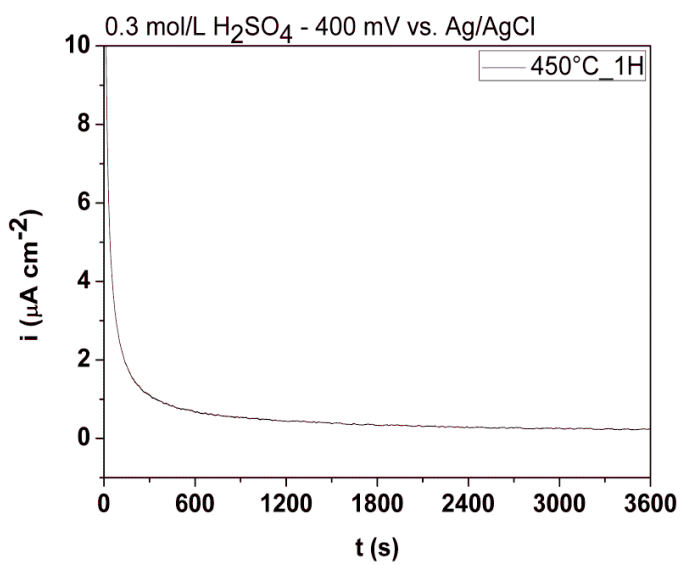

$0.6 \mathrm{~mol} / \mathrm{L} \mathrm{NaCl}+0.3 \mathrm{~mol} / \mathrm{L} \mathrm{H}_{2} \mathrm{SO}_{4}-400 \mathrm{mV}$ vs. $\mathrm{Ag} / \mathrm{AgCl}$

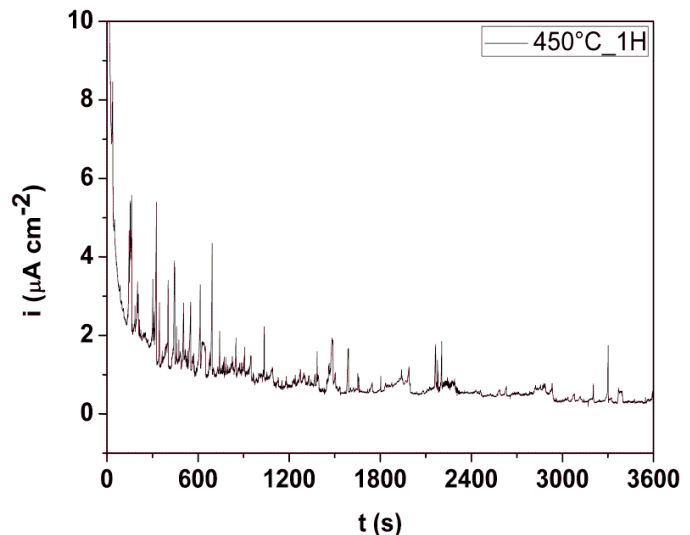

Figure 6. Chronoamperometric recordings at $400 \mathrm{mV}$ showing current peaks corresponding to metastable pitting during immersion in (a) $0.6 \mathrm{~mol} / \mathrm{L} \mathrm{NaCl}$, (b) $0.3 \mathrm{~mol} / \mathrm{L} \mathrm{H}_{2} \mathrm{SO}_{4}$ and (c) $0.6 \mathrm{~mol} / \mathrm{L} \mathrm{NaCl}+0.3 \mathrm{~mol} / \mathrm{L} \mathrm{H}_{2} \mathrm{SO}_{4}$ solutions.

$$
\frac{1}{C_{S C}^{2}}=\frac{2}{\varepsilon \varepsilon_{0} q N_{q} A^{2}}\left(E-E_{F B}-\frac{K_{B} T}{e}\right)
$$

Where $C_{S C}$ is the space charge capacitance of the filme/ electrolyte interface; $\varepsilon$ the dielectric constant, usually taken as 15.6 for the passive film on stainless steel ${ }^{39,40} ; \varepsilon_{0}$ is the vacuum permittivity $\left(8.854 \times 10^{-14} \mathrm{~F} / \mathrm{cm}\right) ; K_{B}$ is the Boltzmann constant $\left(1.38 \times 10^{-23} \mathrm{~J} / \mathrm{K}\right) ; e$ is the electron charge $\left(1.62 \times 10^{-19}\right.$
C); $N_{q}$ is the donor or acceptor concentration (for doping an n-type or p-type semiconductor, respectively); $A$ is the surface area of sample $\left(\mathrm{cm}^{2}\right) ; E$ is the applied potential; $E_{F B}$ is the flat band potential and $T$ is the absolute temperature.

Figure 7 report the Mott-Schottky behavior for the passive films formed on $1 \mathrm{~B}$ steel in $0.6 \mathrm{~mol} / \mathrm{L} \mathrm{NaCl}, 0.3 \mathrm{~mol} / \mathrm{L} \mathrm{H}_{2} \mathrm{SO}_{4}$ and $0.6 \mathrm{~mol} / \mathrm{L} \mathrm{NaCl}+0.3 \mathrm{~mol} / \mathrm{L} \mathrm{H}_{2} \mathrm{SO}_{4}$ solutions. In 0.6 $\mathrm{mol} / \mathrm{L} \mathrm{NaCl}$, the curves exhibit three distinguished regions: 
Table 2. Value of $k$ of samples in the tested solutions.

\begin{tabular}{|c|c|c|c|}
\hline \multirow[b]{2}{*}{ Sample } & \multicolumn{3}{|c|}{$k$ parameter } \\
\hline & $\begin{array}{c}0.6 \mathrm{~mol} / \mathrm{L} \\
\mathrm{NaCl}\end{array}$ & $\begin{array}{c}0.3 \mathrm{~mol} / \mathrm{L} \\
\mathrm{H}_{2} \mathrm{SO}_{4}\end{array}$ & $\begin{array}{c}0.6 \mathrm{~mol} / \mathrm{L} \\
\mathrm{NaCl}+0.3 \\
\mathrm{~mol} / \mathrm{L} \mathrm{H}_{2} \mathrm{SO}_{4}\end{array}$ \\
\hline Annealed & $0.40 \pm 0.04$ & $0.71 \pm 0.03$ & $0.70 \pm 0.07$ \\
\hline $450^{\circ} \mathrm{C}_{-} 1 \mathrm{~h}$ & $0.48 \pm 0.03$ & $0.74 \pm 0.01$ & $0.72 \pm 0.02$ \\
\hline $500^{\circ} \mathrm{C}_{-} 1 \mathrm{~h}$ & $0.47 \pm 0.09$ & $0.79 \pm 0.05$ & $0.75 \pm 0.01$ \\
\hline $550^{\circ} \mathrm{C}_{-} 1 \mathrm{~h}$ & $0.40 \pm 0.01$ & $0.77 \pm 0.02$ & $0.77 \pm 0.00$ \\
\hline $600{ }^{\circ} \mathrm{C} \_1 \mathrm{~h}$ & $0.48 \pm 0.01$ & $0.85 \pm 0.07$ & $0.80 \pm 0.04$ \\
\hline
\end{tabular}

the positive slopes in regions I and III and the negative slope in region II. For samples immersed in $0.3 \mathrm{~mol} / \mathrm{L} \mathrm{H}_{2} \mathrm{SO}_{4}$ and $0.6 \mathrm{~mol} / \mathrm{L} \mathrm{NaCl}+0.3 \mathrm{~mol} / \mathrm{L} \mathrm{H}_{2} \mathrm{SO}_{4}$ solutions, the plots are qualitatively similar, there are two regions with different slopes and we can conclude that the passive films exhibit the same electronic character. For stainless steels, it is often assumed that the semiconducting behavior reflects the duplex character of their oxide films, essentially consisting of a mixed spinel oxide of the $(\mathrm{Fe}, \mathrm{Ni})_{2} \mathrm{CrO}_{4}$ type, rich in $\mathrm{Cr}$ in the inner region and in $\mathrm{Fe}$ in the outer layer ${ }^{41,42}$. The positive slope of the $C^{2}{ }_{S C}$ vs. $E$ plot reveals a n-type semiconductor behavior that is characteristic of a $\mathrm{Fe}^{2+}$-rich spinel; the negative slope, in the other hand, results from the electrochemical behavior of a p-type semiconductor, related to the presence of $\mathrm{Cr}^{3+}$-rich oxide ${ }^{42,43}$.

It should be noted that in $0.6 \mathrm{~mol} / \mathrm{L} \mathrm{NaCl}$, the capacitance responses were lower than in other test solution. This result was considered harmful to passive film stability since an increase in capacitance values results from a reduction in the electron (or hole) depleted layer and an increase in the population of charge carriers, which could be considered detrimental to passive film stability ${ }^{8}$. In addition, one intriguing finding is the presence of a significant linear portion, less marked than the others and appears at potentials more positive than $0.8 \mathrm{~V}$ vs. $\mathrm{Ag} / \mathrm{AgCl}$, presenting features of a n-type semiconductor. This secondary positive slope was generally attributed to the presence of second donor level in the bandgap, which is corresponding to the ionization of the deep donors ${ }^{38,44,45}$.

From the positive and negative slopes of the linear part of Mott Schottky plots, the donor and acceptor densities can be estimated. Table 3 displays the acceptor and donor density for each test solution. The orders of magnitude of calculated doping densities are about $10^{21} \mathrm{~cm}^{-3}$ which are comparable with literature reports ${ }^{38,39,42-44}$. This level of doping is characteristic of heavily doped and disordered passive films ${ }^{46}$.

In general, as can be seen, the donor concentration is always higher than acceptor. The donors and acceptors in semiconducting passive layers are both defects, including cation vacancies, anion vacancies, and cation interstitials. These vacancies act as the dopants i.e., oxygen vacancies and cation interstitials imparting n-type character and cation (a)

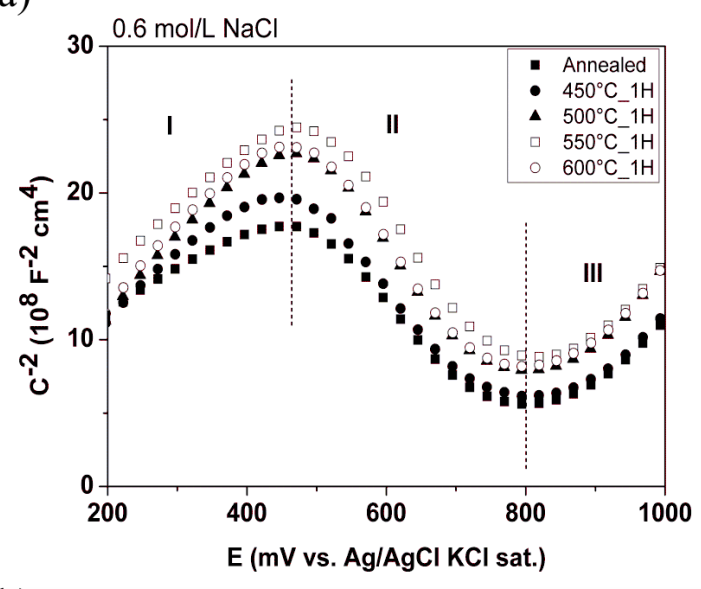

(b)

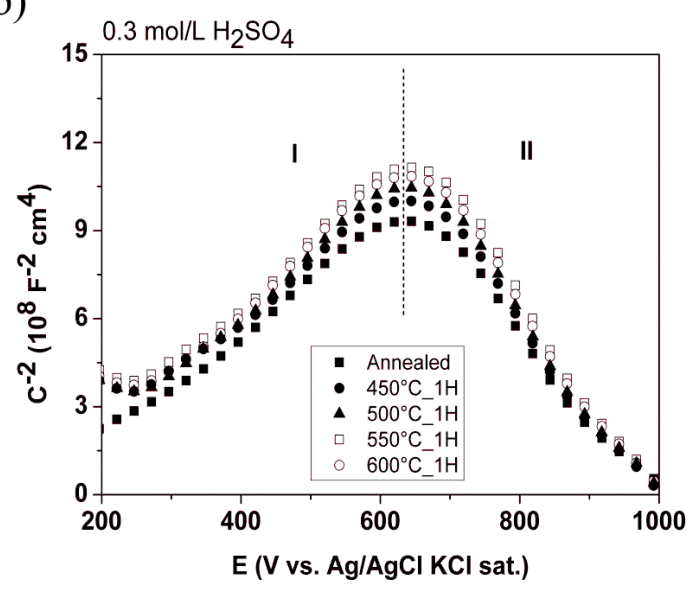

(c)

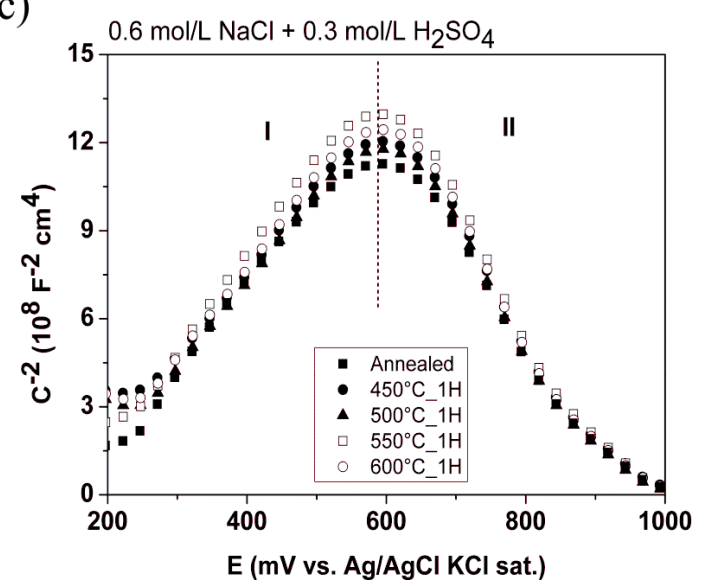

Figure 7. Mott-Schottky plots of $\mathrm{C}^{-2}$ as a function of potential for passive films on cast DSS in (a) $0.6 \mathrm{~mol} / \mathrm{L} \mathrm{NaCl}$, (b) $0.3 \mathrm{~mol} / \mathrm{L} \mathrm{H}_{2} \mathrm{SO}_{4}$ and (c) $0.6 \mathrm{~mol} / \mathrm{L} \mathrm{NaCl}+0.3 \mathrm{~mol} / \mathrm{L} \mathrm{H}_{2} \mathrm{SO}_{4}$ solutions.

vacancies yielding p-type character. The presence of such dopant prevents migration of cations from substrate metal and alloys and the penetration of harmful anions, such as chloride and sulfate ions, from the electrolyte, thereby improving the corrosion resistance. The flux of oxygen vacancy and/or cation interstitials through the passive film is essential to the film 
Table 3. Acceptor and donor density of passive film formed in the tested solutions.

\begin{tabular}{|c|c|c|c|c|c|c|}
\hline \multirow[b]{2}{*}{ Samples } & \multicolumn{2}{|c|}{$0.6 \mathrm{~mol} / \mathrm{L} \mathrm{NaCl}$} & \multicolumn{2}{|c|}{$0.3 \mathrm{~mol} / \mathrm{L} \mathrm{H}_{2} \mathrm{SO}_{4}$} & \multicolumn{2}{|c|}{$0.6 \mathrm{~mol} / \mathrm{L} \mathrm{NaCl}+0.3 \mathrm{~mol} / \mathrm{L} \mathrm{H}_{2} \mathrm{SO}_{4}$} \\
\hline & $\begin{array}{c}N_{D}\left(10^{21} \mathrm{~cm}^{-3}\right) \\
\text { Region I }\end{array}$ & $\begin{array}{c}N_{A}\left(10^{21} \mathrm{~cm}^{-3}\right) \\
\text { Region II }\end{array}$ & $\begin{array}{c}N_{D}\left(10^{21} \mathrm{~cm}^{-3}\right) \\
\text { Region I }\end{array}$ & $\begin{array}{c}N_{A}\left(10^{21} \mathrm{~cm}^{-3}\right) \\
\text { Region II }\end{array}$ & $\begin{array}{c}N_{D}\left(10^{21} \mathrm{~cm}^{-3}\right) \\
\text { Region I }\end{array}$ & $\begin{array}{c}N_{A}\left(10^{21} \mathrm{~cm}^{-3}\right) \\
\text { Region II }\end{array}$ \\
\hline Annealed & 2.36 & 1.33 & 4.42 & 2.56 & 3.13 & 2.16 \\
\hline $450^{\circ} \mathrm{C} \_1 \mathrm{~h}$ & 2.10 & 1.37 & 4.37 & 2.51 & 3.11 & 2.19 \\
\hline $500^{\circ} \mathrm{C} \_1 \mathrm{~h}$ & 2.05 & 1.34 & 4.05 & 2.41 & 3.09 & 2.15 \\
\hline $550^{\circ} \mathrm{C} \_1 \mathrm{~h}$ & 2.26 & 1.30 & 3.72 & 2.19 & 2.80 & 1.92 \\
\hline $600^{\circ} \mathrm{C} \_1 \mathrm{~h}$ & 1.96 & 1.34 & 3.87 & 2.35 & 2.96 & 1.93 \\
\hline
\end{tabular}

growth process ${ }^{47-49}$. Following this concept, the dominant point defects in the passive film are considered to be oxygen vacancies and/or cation interstitial acting as electron donors. Moreover, the donor density of annealed sample is higher than aged samples. The doping densities decrease is related to the reduction of the number of point defects in the film. This trend may be an indication of the beneficial effect of short time aging on the passivation behavior of steel, which is in agreement with chronoamperometric measurements.

\section{Conclusions}

The cast copper alloyed duplex stainless steel ASTM A890 grade 1B were heat treated for short time. The microstructure was characterized and electrochemical tests were performed. The main conclusions are:

- $\quad$ The polarization results in $0.6 \mathrm{~mol} / \mathrm{L} \mathrm{NaCl}$ showed a small anodic current peak occurred at around 400 $\mathrm{mV}$ vs. $\mathrm{Ag} / \mathrm{AgCl}$. The instability observed may be an indication of the copper effect on the passivation behavior of samples in chloride medium.

- Metastable pit nucleates preferentially in the inclusions as observed after potentiodynamic polarization.

- Chronoamperometric measurements at $400 \mathrm{mV}$ vs. $\mathrm{Ag} / \mathrm{AgCl}$ showed a high electrochemical activity for the samples in $0.6 \mathrm{~mol} / \mathrm{L} \mathrm{NaCl}$, suggesting that $3.01 \% \mathrm{Cu}$ stainless steel is susceptible to pitting corrosion.

- Donor density of the annealed sample film is higher than the aged one, showing a possible beneficial effect of short time aging on the passivation behavior of steel.

\section{Acknowledgments}

The authors wish to acknowledge the financial support by Coordenação de Aperfeiçoamento de Pessoal de Nível Superior (Capes) and Petrobras.

\section{References}

1. Li P, Zhao Y, Liu Y, Zhao Y, Xu Z, Yang C, Zhang T, Gu T, Yang K. Effect of $\mathrm{Cu}$ addition to 2205 duplex stainless steel on the resistance against pitting corrosion by the Pseudomonas aeruginosa biofilm. Journal of Materials Science \& Technology. 2017;33(7):723-727.

2. Bastos IN, Tavares SSM, Dalard F, Nogueira RP. Effect of microstructure on corrosion behavior of super duplex stainless steel at critical environment conditions. Scripta Materialia. 2007;57(10):913-916.

3. Tavares SSM, Pardal JM, Lima LD, Bastos IN, Nascimento AM, Souza JA. Characterization of microstructure, chemical composition, corrosion resistance and toughness of a multipass weld joint of superduplex stainless steel UNS S32750. Materials Characterization. 2007;58(7):610-616.

4. Otarola T, Hollner S, Bonnefois B, Anglada A, Coudreuse L, Mateo A. Embrittlement of a superduplex stainless steel in the range of $550-700{ }^{\circ} \mathrm{C}$. Engineering Failure Analysis. 2005;12(6):930-941.

5. Chen TH, Weng KL, Yang JR. The effect of high-temperatures exposure on the microstructural stability and toughness property in a 2205 duplex stainless steel. Materials Science and Engineering: A. 2002;338(1-2):259-270.

6. Nilsson JO. Super duplex stainless steels. Materials Science and Technology. 1992;8(8):685-700.

7. Gunn RN. Duplex stainless steels: microstructure, properties and applications. Cambridge, England: Abington Publishing; 1997.

8. Ujiro T, Satoh S, Staehle RW, Smyrl WH. Effect of alloying $\mathrm{Cu}$ on the corrosion resistance of stainless steels in chloride media. Corrosion Science. 2001;43(11):2185-2200.

9. Sourisseau T, Chauveau E, Baroux B. Mechanism of copper action on pitting phenomena observed on stainless steels in chloride media. Corrosion Science. 2005;47:1097-1117.

10. Oguzie EE, Li J, Liu Y, Chen D, Li Y, Yang K, Wang F. The effect of $\mathrm{Cu}$ addition on the electrochemical corrosion and passivation behavior of stainless steels. Electrochimica Acta. 2010;55(17):5028-5035. 
11. Olsson COA, Landolt D. Passive films on stainless steels - Chemistry, structure and growth. Electrochimica Acta. 2003;48(9):1093-1104.

12. Raja KS, Jones DA. Effects of dissolved oxygen on passive behavior of stainless alloys. Corrosion Science. 2006:48(7):16231638 .

13. Kong DS, Chen SH, Wang C, Yang W. A study of the passive films on chromium by capacitance measurement. Corrosion Science. 2003;45(4):747-758.

14. Banas J, Mazurkiexicz A. The effect of copper on passivity and corrosion behavior of ferritic and ferritic-austenitic stainless steels. Materials Science and Engineering: A. 2000;277(12):183-191.

15. Shu J, Bi H, Li X, Xu Z. The effect of copper and molybdenum on pitting corrosion and stress corrosion cracking behavior of ultra-pure ferritic stainless steels. Corrosion Science. 2012;57:8998.

16. Tavares SSM, Pardal JM, Almeida BB, Mendes MT, Freire JLF, Vidal AC. Failure of superduplex stainless steel flange due to inadequate microstructure and fabrication process. Engineering Failure Analysis. 2018;84:1-10.

17. Rovere CAD, Santos FS, Silva RAR, Souza CAC, Kuri SE. Influence of long-term low-temperature aging on the microhardness and corrosion properties of duplex stainless steel. Corrosion Science. 2013;68:84-90.

18. Alonso-Falleiros N, Hakim A, Wolynec S. Comparison between potentiodynamic and potentiostatic tests for pitting potential measurement of duplex stainless steels. Corrosion (Houston). 1999;55(5):443-448.

19. Sedriks AJ. Corrosion of Stainless Steels. $2^{\text {nd }}$ ed. New York: John Wiley \& Sons; 1996.

20. Yang Y, Yan B, Wang J. The effect of large heat input on the microstructure and corrosion behavior of simulated heat affected zone in 2205 duplex stainless steel. Corrosion Science. 2011;53(11):3756-3763.

21. Moayed MH, Newman RC. Evolution of current transients and morphology of metastable and stable pitting on stainless steel near the critical pitting temperature. Corrosion Science. 2006;48(4):1004-1018.

22. Salinas-Bravo VM, Newman RC. An alternative method to determine critical pitting temperature of stainless steels in ferric chloride solution. Corrosion Science. 1994;36(1):67-77.

23. Xia DH, Song S, Zhu R, Behnamiana Y, Shena C, Wang J, Luo J, Lu Y, Klimas S. A mechanistic study on thiosulfate-enhanced passivity degradation of Alloy 800 in chloride solutions Dahai. Electrochimica Acta. 2013;111:510-525.

24. Zhu RK, Lu BT, Luo JL, Lu YC. Effect of cold work on surface reactivity and nano-hardness of alloy 800 in corroding environments. Applied Surface Science. 2013;270:755-762.

25. Boissy C, Alemany-Dumont C, Normand B. EIS evaluation of steady-state characteristic of 316L stainless steel passive film grown in acidic solution. Electrochemistry Communications. 2013;26:10-12.
26. Miyata Y, Handa T, Takazawa H. An analysis of current fluctuations during passive film breakdown and repassivation in stainless alloys. Corrosion Science. 1990;31:465-470.

27. Jiang J, Xu D, Xi T, Shahzad MB, Khan MS, Zhao J, et al. Effects of aging time on intergranular and pitting corrosion behavior of $\mathrm{Cu}$-bearing $304 \mathrm{~L}$ stainless steel in comparison with 304L stainless steel. Corrosion Science. 2016;113:46-56.

28. Jeon SH, Kim ST, Choi MS, Kim JS, Kim KT, Park YS Effects of cerium on the compositional variations in and around inclusions and the initiation and propagation of pitting corrosion in hyperduplex stainless steels. Corrosion Science. 2013;75:367-375.

29. Jeon SH, Kim HJ, Kong KH, Park YS. Effects of copper addition on the passivity and corrosion behavior of $27 \mathrm{Cr} 7 \mathrm{Ni}$ hyper duplex stainless steels in sulfuric acid solution. Materials Transactions. 2015;56(1):78-84.

30. Guo J, Seo M, Sato Y, Hultquist G, Leygraf C, Sato N. Eletrochemical behavior and surface composition of copper containing ferritic stainless steel in sulfuric acid solution. Corrosion Engineering. 1986;35(5):283-288.

31. Yamamoto A, Ashjura T, Kamisaka E. Mechanism of improvement on corrosion resistance by copper addition to ferritic stainless steels. Corrosion Engineering. 1986;35(8):448-454.

32. Lakatos-Varsányi M, Falkenbergb F, Olefjordb I. The influence of phosphate on repassivation of 304 stainless steel in neutral chloride solution. Electrochimica Acta. 1998;43(1-2):187-197.

33. Lakatos-Varsányi M, Wegrelius L, Olefjord I. Dissolution of stainless steel in artificial saliva. Journal of Oral and Maxillofacial Implants. 1997;12(3):387-398.

34. Qiao YX, Zheng YG, Ke W, Okafor PC. Electrochemical behaviour of high nitrogen stainless steel in acidic solutions. Corrosion Science. 2009;51(5):979-986.

35. Dean MH, Stimming U. The electronic properties of disordered passive films. Corrosion Science. 1989;29:199-211.

36. Sunseri C, Piazza S, Di Quarto F. Photocurrent spectroscopic investigations of passive films on chromium. Journal of the Electrochemical Society. 1990;137(8):2411-2417.

37. Craig BG. Fundamental Aspects of Corrosion Films in Corrosion Science. New York: Plenum Press; 1991.

38. Montemor MF, Ferreira MGS, Hakiki NE, Belo MC. Chemical composition and electronic structure of the oxide films formed on 316L stainless steel and nickel based alloys in high temperature aqueous environments. Corrosion Science. 2000;42(9):16351650 .

39. Fattah-Alhosseini A, Soltani F, Shirsalimi F, Ezadi B, Attarzadeh $\mathrm{N}$. The semiconducting properties of passive films formed on AISI $316 \mathrm{~L}$ and AISI 321 stainless steels: A test of the point defect model (PDM). Corrosion Science. 2011;53(10):31863192 .

40. MacDonald DD, Ismail KM, Sikora E. Characterization of the passive state on zinc. Journal of the Electrochemical Society. 1998;145(9):3141-3149. 
41. Pieretti EF, Manhabosco SM, Dick LFP, Hinder S, Costa I. Localized corrosion evaluation of the ASTM F139 stainless steel marked by laser using scanning vibrating electrode technique, X-ray photoelectron spectroscopy and Mott-Schottky techniques. Electrochimica Acta. 2014;124:150-155.

42. Taveira LV, Montemor MF, Belo MC, Ferreira MG, Dick LFP. Influence of incorporated $\mathrm{Mo}$ and $\mathrm{Nb}$ on the Mott-Schottky behavior of anodic films formed on AISI 304L. Corrosion Science. 2010;52(9):2813-2818.

43. Hakiki NE, Rondot SB, Belo MC. The electronic structure of passive films formed on stainless steels. Corrosion Science. 1995;37(11):1809-1822.

44. Hamadou L, Kadri A, Benbrahim N. Impedance investigation of thermally formed oxide films on AISI 304L stainless steel. Corrosion Science. 2010;52(3):859-864.
45. Nogami G. Characterization of semiconductor electrodes with a deep impurity level. Journal of the Electrochemical Society. 1982;129(10):2219-2223.

46. Hamadou L, Kadri A, Benbrahim N. Characterization of passive films formed on low carbon steel in borate buffer solution $(\mathrm{pH}$ 9.2) by electrochemical impedance spectroscopy. Applied Surface Science. 2005;252(5):1510-1519.

47. Luo H, Dong CF, Li XG, Xiao K. The electrochemical behavior of 2205 duplex stainless steel in alkaline solutions with different $\mathrm{pH}$ in the presence of chloride. Electrochimica Acta. 2012;64:211-220.

48. Amri J, Souier T, Malki B, Baroux B. Effect of the final annealing of cold rolled stainless steels sheets on the electronic properties and pit nucleation resistance of passive films. Corrosion Science. 2008;50(2):431-435.

49. Fattah-Alhosseni A, Vafaeian S. Passivation behavior of a ferritic stainless steel in concentrated alkaline solutions. Journal of Materials Research and Technology. 2015;4(4):423-428. 